\title{
Using Supplementary Video in Multimedia Instruction as a Teaching Tool to Increase Efficiency of Learning and Quality of Experience
}
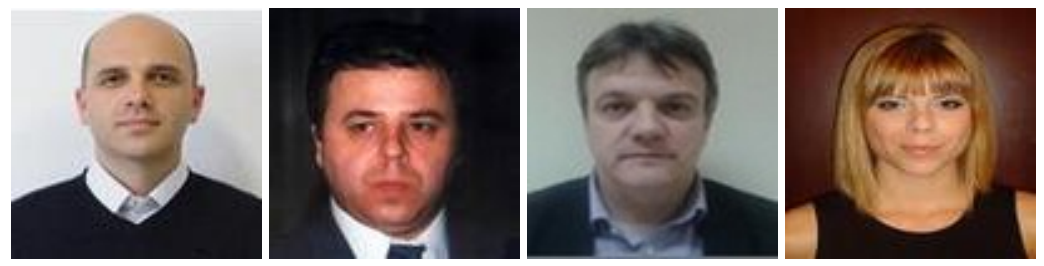

Milos Ljubojevic ${ }^{1}$, Vojkan Vaskovic ${ }^{2}$, Srecko Stankovic ${ }^{3}$, and Jelena Vaskovic ${ }^{2}$ ${ }^{1}$ Academic and Research Network of Republic of Srpska, BiH, ${ }^{2}$ University of Belgrade, Serbia, ${ }^{3}$ City Hall of Banja Luka, BiH

\section{Abstract}

The main objective of this research is to investigate efficiency of use of supplementary video content in multimedia teaching. Integrating video clips in multimedia lecture presentations may increase students' perception of important information and motivation for learning. Because of that, students can better understand and remember key points of a lecture. Those improvements represent some important learning outcomes. This research showed that segmentation of teaching materials with supplementary video clips may improve lecture organization and presentation in order to achieve effective teaching and learning. The context of the video content and the position of supplementary video clips in teaching material are important influences on factors for motivation and efficiency of learning. This research presents the effects of the use of supplementary videos with different context of content (entertainment and educational) as well as the effects of their position within the teaching material. The experimental results showed that the most efficient method of use of supplementary video is integration with educational video content in the middle of a lecture. This position of video insertion provides the best results. The context of video content influences efficiency of learning also. Entertainment video was not as efficient as educational, but it can be used to engage and motivate students for learning. The given results have been confirmed with a subjective assessment of students' quality of experience with different methods of embedding video clips. 
Keywords: Learning efficiency; student motivation; multimedia instruction; supplementary video; quality of experience

\section{Introduction}

Web-based instruction in the educational and training domains plays an important role, and its effects on learning outcomes, performance, and student satisfaction are important research topics (Olson \& Wisher, 2002). Integration of video clips in teaching materials has recently attracted more attention in academic research.

The outcomes of using supplementary videos are increasing student activity and efficiency of the teaching process. An important issue is establishing a methodology of embedding video clips in multimedia teaching material in order to improve the learning process (Kay, 2012). Distance learning and college courses where the students are working individually on their projects after class are especially suitable for testing of new methods aimed at improvement of students' work.

The main motivation for testing the effects of video clip integration into multimedia presentation is that visual stimulation with a media application familiar to the student population can increase their engagement. It is well known that Internet video traffic is constantly increasing its share of consumer Internet traffic. Social media applications such as Facebook, YouTube, blogs, and wikis can be used as supplemental materials in the teaching process (Burke, Snyder, \& Rager, 2009).

The selection of appropriate video clips and methodology for their display within the teaching materials represents an important issue for curriculum design, leading to positive learning outcomes (McConville \& Lane, 2006). The cognitive theory of multimedia learning shows that it is necessary to select relevant information and organize it into a verbal and pictorial model (Mayer, 2001). Using appropriate teaching media and methods to organize and present only relevant information may also increase the efficiency of the self-learning process (Ruiji, 2012). Evaluating the effectiveness of the use of teaching materials in video format in distance learning environments and the measuring of "viewer engagement" is important for improvement of the learning process (Stiubiener et al., 2012).

An important aspect of the learning process is students' satisfaction, especially in the case of online learning (Roach \& Lemasters, 2006). Considering this theory, students' satisfaction, as an important outcome of a multimedia learning process, should be analyzed more closely. The quality of student satisfaction and experience depends on the method of usage of video clips in designing linear educational video materials. Therefore, the quality of the learning process may be described also with quality of experience (QoE). 
In this paper, the efficiency of learning and quality of experience for different types of video clips and methods for integration in multimedia lecture presentations are analyzed.

\section{Video as a Factor of Influence in Motivation, Satisfaction, and Successful Learning}

Modern teaching processes are based on the use of multimedia teaching materials and the Internet. The cognitive theory of multimedia learning represents a foundation for the implementation of multimedia educational content presentation. This theory explains the significance of the modality principle in the learning process, as shown in Figure 1.

In order to efficiently process multimedia information it is necessary to select relevant information and organize it into a verbal and pictorial model. Processing the information is performed in two channels after receiving the auditory and visual information that appears in the working memory as verbal and pictorial information models. A rational use of resources is very important, so design of multimedia presentation is a crucial factor for the learning process outcome (Mayer, 2001; Moreno \&Mayer, 1999).

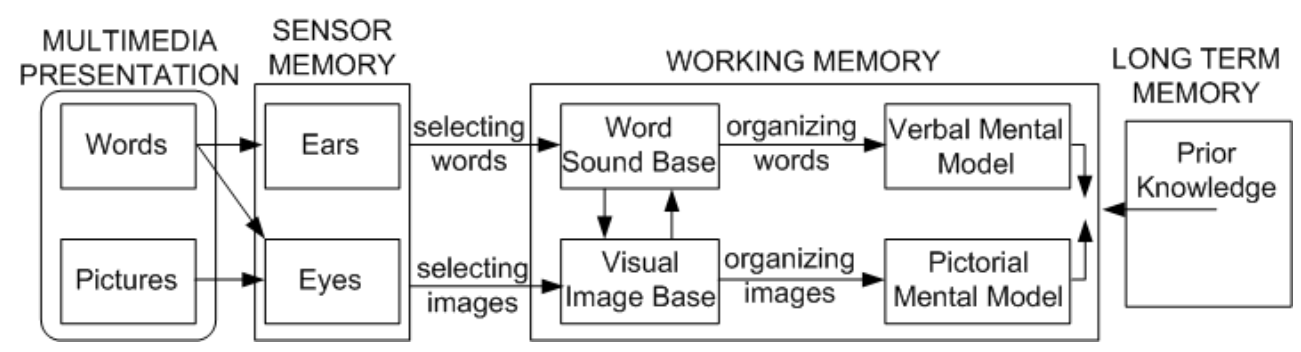

Figure 1. The cognitive theory of multimedia learning (Mayer, 2001).

Cognitive load theory, educational research, and instructional design are closely related, thus they should be analyzed together to achieve the best learning results (De J ong, 2010). Previous research also shows that the efficiency of the learning process is closely related to interaction between motivational and cognitive variables (Valle et al., 2003).

Multimedia technology has been exploited often for improving teaching and learning. Videos are a tool for engaging the verbal (linguistic), visual (spatial), and musical (rhythmic) intelligence of the student in the learning process, especially in the selflearning process (Gardner, 2000). Positive effects of features of video clips (multisensory, dynamic and capable of engaging the viewer's attention) were often used in engineering education (Marques, 2012). 
Different methods of embedding and different contexts of supplementary video content can be used in the teaching process. Teachers are using multimedia presentation prepared for the course as well as additional, supplementary videos. Supplementary videos may have different contexts. Two of them are important for this research: The first is that they are closely related to the presented lecture topic and the second context is entertainment used for capturing the attention and interest of the students. Methods for integration and use of different contexts of supplementary videos in multimedia education materials are important tasks for research aiming to improve the learning process.

In this research, the purpose of supplementary video material use is to increase student's attention on the topic of the lecture. In order to increase learning quality, two important goals should be achieved: reducing cognitive load and increasing student's attention. Besides educational and entertainment content, it is possible to use commercial content as supplementary video. Although the commercial content may contribute to reducing the cognitive load of the student, this type of context potentially may take away students' attention from the topic of the lecture and focus it on the commercial content. Due to that, supplementary videos with commercial content have been less relevant to this research than educational and entertainment content. In future research, the influence of supplementary videos with commercial content on students' attention should be investigated.

Previous research explored the results of the use of videos as an educational tool (Bravo et al., 2011). In this study the authors used educational videos with a duration of approximately four minutes. They used a teaching platform based on Moodle and YouTube channels for reproduction. The study showed that streaming videos used as supporting material for learning had a positive effect upon students' perception regarding the enhancement of their learning motivation. The study emphasized that proper definition of content and amount of information delivered through supplemental video is an important task to solve. Durations of videos and methodologies of displaying them influence the effectiveness of learning and student satisfaction. An important result of this research is that streaming supplemental videos improve students' ability to learn in an autonomous way.

Hsin and Cigas (2013) used short videos to enhance student satisfaction and motivation for an online introductory course in computer science/mathematics. They achieved a significantly higher percentage of involved students and their average grades increased. Another method to engage and to motivate students is showing entertainment videos (Steffes \& Duverger, 2012). As Steffes and Duverger reported, showing supplementary videos within an entertainment context at the beginning of the class can be used to increase the positive mood of the students. Both previous studies, Bravo et al. (2011) and Steffes and Duverger (2012), emphasize the importance of the proper design of supplementary video content and the methodology of displaying video to students. 
Donkor (2011) showed that use of video-based instructional materials for teaching practical skills at a distance also appears promising.

One of the key questions is the quality of experience (QoE) achieved with the presented multimedia materials. This problem is more interesting if the different contexts of the video content are merged. In the research presented in Le Callet et al. (2012), the authors defined experience as an individual's stream of perception and interpretation of one or multiple events. On the other hand, quality is defined as an outcome of an individual's comparison and judgment process, which includes perception, reflection about the perception, and description of the outcome.

Finally, a working definition of quality of experience is:

Quality of Experience (QoE) is the degree of delight or annoyance of the user of an application or service. It results from the fulfillment of his or her expectations with respect to the utility and/or enjoyment of the application or service in the light of the user's personality and current state. (Le Callet et al., 2012)

The definition of quality of experience gives a framework for analyzing the efficiency of delivery of video content using the Internet. Ljubojevic et al. (2013) analyzed linear internet video advertising efficiency using QoE methods. Another important task is the influence of the delivery of supplementary video used in the teaching process on students' quality of experience.

Therefore, students' quality of experience and learning outcome may depend on the context of inserted supplementary videos and the method for embedding video into teaching material.

\section{Method}

Previous research findings showed that segmentation of multimedia teaching materials enables easier processing of complex information by reducing high cognitive load. Students with a low level of prior knowledge learned more efficiently if segmented material was presented instead of continuous material (Spanjers et al., 2011). This finding is especially important for novices in the learning process.

In our study, the participants in the experiment were students who attended the class for the first time and had a lower level of prior knowledge. Therefore, the efficiency of different methods of segmentation of multimedia teaching material in learning for novices was analyzed. Due to the fact that video with different video content types is inserted in multimedia learning materials, supplementary videos have a different 
influence on students' motivation and QoE. The efficiency of different methods for integrating those videos should be investigated in detail.

The teacher has to decide how he wants to use video clips, where and when to embed them into multimedia learning material (Berk, 2009). Previous research described the effectiveness of videos embedded in multimedia teaching materials and their influence on the improvement of teaching (Pryor \& Bitter, 2008; Borko et al., 2008). This choice has a strong influence on the students' QoE and the efficiency of the learning process. The instructional design model is also important in developing teaching skills (Isman et al., 2012). In order to analyze the multimedia learning quality process and level of student motivation for learning, especially if supplementary video streaming was used within the lecture, the quality of experience assessment should be used.

\section{Testing Methodology}

Important aspects of this study are principles for designing multimedia teaching content and presenting supplementary videos. A method for assessment of the efficiency of learning and student's QoE was also proposed.

In this study two influence factors in motivation and efficiency of learning were tested: the context of inserted supplementary video and position of the embedded videos into teaching material.

Two contexts of videos were used: the entertainment context of the video and the educational context similar to a lecture. Methods for embedding the videos were analyzed in the sense of the position of the supplementary video regarding the main multimedia teaching material. Three possible methods were tested: displaying supplementary videos before, in the middle, and after the lecture.

In order to simulate spatial and temporal separation between the students and the professor (main characteristic of distance learning and the self-learning process), multimedia materials created for the experiment were presented to the students in a multimedia classroom. Two assistants also assisted as technical support during the lecture presentation.

Each of the applied methods for embedding supplementary videos was separately tested. After the lecture presentation, using one of the methods, participants had a 60 minute break and then the testing was performed. Students answered 20 questions related to the lesson that was presented. By analyzing the given testing results, the efficiency of different methods for inserting supplementary video may be compared.

A subjective assessment of the user's quality of experience was also conducted. The testing was performed according to the subjective video quality assessment methods for multimedia applications described by Recommendation ITU-T P.910 (ITU-T, 1999). During the testing, a single test condition (one multimedia education content with 
supplementary video) was presented to students once only. Then they gave a quality rating on an Absolute Category Rating (ACR) scale. By use of the previously described methodology, the subjective assessment of the quality of experience (QoE) was conducted immediately after the presentation of the teaching materials.

In order to assess the subjective perception of the method for the presentation of lecture content, participants answered carefully chosen questions, listed in Table 1.

Table 1

Assessment Questions

\begin{tabular}{|l|l|}
\hline No. & \multicolumn{1}{c|}{ Question } \\
\hline 1 & Were the directions for participating in experiment sufficient? \\
\hline 2 & Did you find the quality of presenting a lecture sufficient? \\
\hline 3 & $\begin{array}{l}\text { Did you think video and audio quality of supplementary video } \\
\text { stream was good? }\end{array}$ \\
\hline 4 & Were you able to maintain the attention level during the session? \\
\hline 5 & Do you think that you correctly answered the questions? \\
\hline 6 & Was it easy to answer the questions? \\
\hline
\end{tabular}

According to Recommendation ITU-T P.910 and assessment and rating of the quality of experience, a five level mean opinion score (MOS) scale was used as presented in Table 2.

Table 2

Scale for Quality of Experience Rating and Gradation

\begin{tabular}{|c|c|}
\hline Mean opinion score (MOS) & Explanation \\
\hline 5 & Excellent \\
\hline 4 & Good \\
\hline 3 & Fair \\
\hline 2 & Poor \\
\hline 1 & Bad \\
\hline
\end{tabular}

This research has several limitations, which are related to deeper analysis that needs a longer period of testing. The performed experiment should be applied for a whole semester with the participation of a number of different classes of students. Several different curriculums should be used in research for a deeper analysis and an efficient comparison of results. Those limitations should be overcome in future research. 


\section{Participants and Testing Environment}

The research was performed at a university located in Bosnia and Herzegovina. The multimedia classroom is well-equipped for advanced multimedia presentations and high speed internet access.

The participants were 46 undergraduate students who attended the same academic course. During the preparation of the experiment students were informed about the testing procedure. In order to motivate students for serious participation they were informed that they would receive extra credits for their course grade based on their individual performance. Participants filled in questionnaires regarding personal data, prior experience related to multimedia learning methods, and prior knowledge about the topics covered in the multimedia testing materials.

Analysis of collected data showed that participants had a similar level of prior knowledge about the multimedia learning and topics that were presented in the multimedia teaching materials. Therefore, it may be assumed that there was homogeneity in learners' prior knowledge and skills related to the teaching process. Demographic data showed that out of 46 participants, 28 were male and 18 were female with the average age under 22 (93\%).

\section{Design of the Testing of Multimedia Learning Material}

The multimedia teaching material was designed for the purpose of this research using topics defined in the course curriculum. The teaching material consisted of two parts: the main multimedia educational material and the supplementary videos. The main multimedia education material was created using video lectures recorded by using a professional video camera and PowerPoint presentations. Video lectures and PowerPoint presentations were merged so the text of the PowerPoint presentation, audio information and effect of occasional appearance of the instructor on the screen were used to achieve better knowledge transfer.

Supplementary videos that were used were downloaded from YouTube keeping in mind users' interests and the number of views. Video clips were inserted and presented before, in the middle, and after the main multimedia educational material. The method of integrating two videos by displaying only one of them on the screen, if the user has no control over the presented video, may be described as a linear method of multimedia presentation. The supplementary videos have two contexts. The first context is entertainment and the second one is closely related to the lecture.

For designing one dataset of teaching material one main multimedia educational material content and two videos with previously described contexts (entertainment and educational) were used. From the aspect of usage of supplementary video, three types of multimedia test material were created: 
- Supplementary videos were not used at all and the lecture was presented continuously;

- Supplementary video with the entertainment context was used;

- Supplementary video with the educational context closely related to the lecture topic was used.

In order to test the influence of the position of supplementary video within the multimedia presentation, the video was displayed at the beginning, in the middle, and at the end of the main multimedia educational material, as shown in Figure 2. Therefore, for each type of multimedia materials three different subtypes were created.

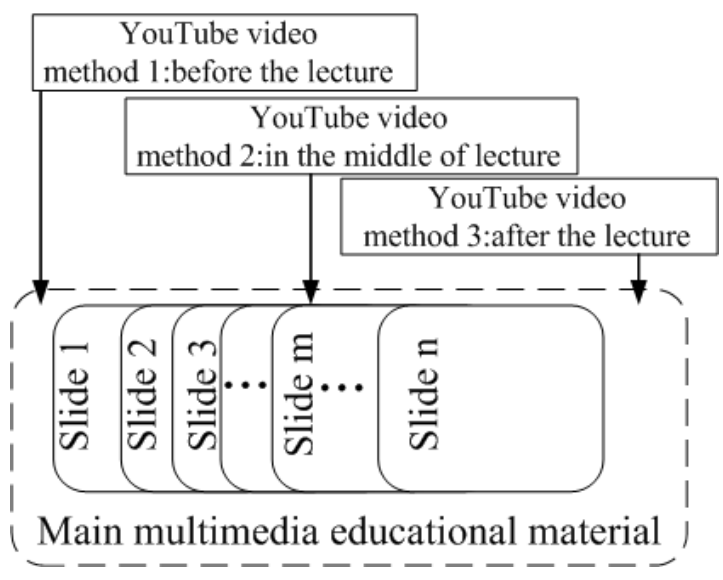

Figure 2. Principle of inserting the supplementary video in lecture presentation.

According to the proposed methodology the following types of multimedia teaching materials were created:

- main multimedia without supplementary video and application of continual presentation of lecture (M_nv);

- main multimedia with educational supplementary video inserted at the beginning ( $M_{-}$ed 1), middle ( $M_{-}$ed 2), and at the end of the presentation (M_ed 3);

- main multimedia with entertainment supplementary video inserted at the beginning (M_ent 1), middle (M_ent 2), and at the end of the presentation (M_ent 3).

The influence of the segmentation method by inserting supplementary video within the presentation of the lecture content was analyzed comparing the previously described methods of lecture presentation. 


\section{Results}

For every type of multimedia education material which was created for this research, the level of acquired knowledge and student's quality of experience were tested. In order to describe key research variables, two research instruments were used. Test questions and results illustrated with average number of correct answers, median value, and standard deviation were used to measure the level of the acquired knowledge and to describe the testing procedure. The assessment of students' quality of experience was performed using a MOS scale with the five levels.

If the presentation of the lecture is continuous, without inserting supplementary videos, which is considered as a method that provides acquiring a reference level of knowledge, two remaining methods may describe possible improvements achieved by inserting different videos.

Tested methods of embedding the supplementary videos were:

- main multimedia without supplementary video using continual lecture presentation (M_nv);

- main multimedia with educational supplementary video inserted at the beginning (M_ed 1);

- main multimedia with educational supplementary video inserted in the middle (M_ed 2);

- main multimedia with educational supplementary video inserted at the end of the presentation (M_ed 3);

- main multimedia with entertainment supplementary video inserted at the beginning (M_ent 1);

- main multimedia with entertainment supplementary video inserted in the middle (M_ent 2);

- main multimedia with entertainment supplementary video inserted at the end of the presentation (M_ent 3).

The results of testing the acquired knowledge and student's quality of experience are analyzed and presented in Table 3 and Table 4, respectively. In Table 3, the average number of correct answers for every tested method of embedding and displaying supplementary videos is presented. 
Table 3

Results of Testing of Acquired Knowledge

\begin{tabular}{|c|c|c|c|c|c|c|c|c|}
\hline & & \multicolumn{7}{|c|}{ Methods of embedding and displaying supplementary video } \\
\hline \multirow{4}{*}{ 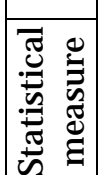 } & & $\mathrm{M} n \mathrm{nv}$ & $\mathrm{M}$ ed 1 & $\mathrm{M}$ ed 2 & $M$ ed 3 & $\mathrm{M}$ ent 1 & $\mathrm{M}$ ent 2 & $M$ ent 3 \\
\hline & AV & 12.22 & 13.78 & 15.50 & 12.85 & 13.13 & 13.76 & 12.33 \\
\hline & Med & 12.00 & 14.00 & 15.00 & 12.00 & 13.00 & 14.00 & 12.00 \\
\hline & Std & 3.11 & 2.51 & 2.29 & 2.52 & 2.00 & 2.06 & 2.44 \\
\hline
\end{tabular}

AV - Average number of correct answers, Med - Median value, Std - Standard deviation

The least number of correct answers was in the case of continual presentation of lecture content. It illustrates that segmentation by inserting video clips may increase memory and better understanding in the learning process. Therefore, the results showed that methods based on the insertion of videos in multimedia teaching materials gave a higher number of correct answers regardless of the position or the context of supplementary videos.

The presented results indicate that a more efficient method for increasing the students' participation and deeper learning is to display the educational context of supplementary video clips instead of inserting entertainment videos.

The experimental results also showed that the biggest influence on efficiency of learning is the method that is based on inserting videos in the middle of the lecture presentation. The results were the same for both contexts of the supplementary videos. In the case of inserting the videos in the middle, the data were closest to the mean and the standard deviation was smallest, so the answers were fairly uniform. It confirmed the superiority of inserting video clips in the middle of the lecture.

The results of knowledge testing (average number of correct answers) for different methods of inserting supplementary video clips are illustrated in Figure 3. 


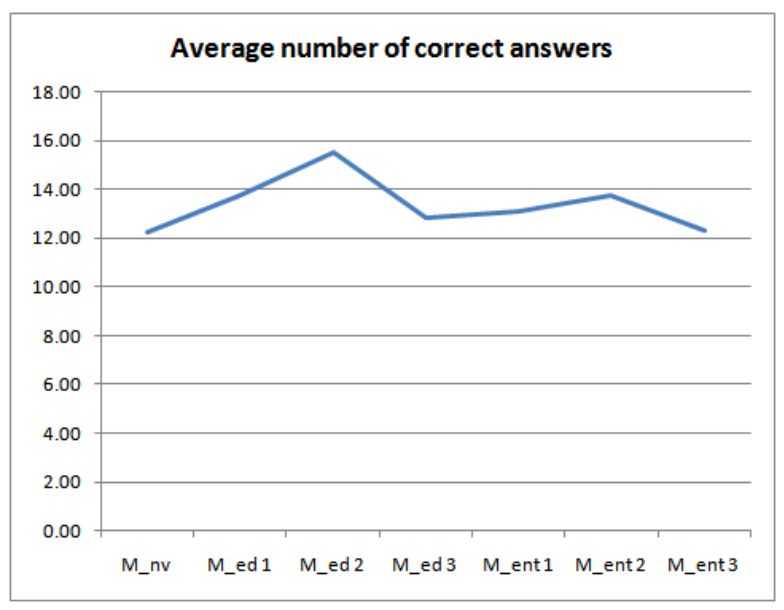

Figure 3. Illustration of average number of correct answers.

Experimental results of the subjective assessment of quality of experience for every tested method of embedding supplementary video, presented in Table 4, showed that participants were satisfied with the preparation of the experiment process, technical aspects of the presented material, and quality of the lecture presentation.

Table 4

The Results for Assessment of Quality of Experience

\begin{tabular}{|c|c|c|c|c|c|c|c|}
\hline & \multicolumn{7}{|c|}{ MOS values } \\
\hline & M nv & M ed 1 & M ed 2 & M ed 3 & M_ent 1 & M_ent 2 & M ent 3 \\
\hline Question 1 & 5 & 5 & 5 & 5 & 5 & 5 & 5 \\
\hline Question 2 & 5 & 5 & 5 & 5 & 5 & 5 & 5 \\
\hline Question 3 & 5 & 5 & 5 & 5 & 5 & 5 & 5 \\
\hline Question 4 & 4.1 & 4.7 & 4.8 & 4.5 & 4.2 & 4.4 & 4.2 \\
\hline Question 5 & 3.4 & 4 & 4.2 & 3.9 & 3.6 & 3.7 & 3.5 \\
\hline Question 6 & 3.9 & 4.3 & 4.3 & 4.1 & 4.1 & 4.2 & 4 \\
\hline
\end{tabular}

The attention of participants was maintained at the highest level during the session with the use of educational supplementary videos, especially if they were inserted in the middle of the presentation. The usage of complementary video with an educational context gave the best results regarding students' self-confidence in the answering of test questions.

An illustration of the MOS results for questions 4, 5 and 6, that closely describe quality of experience, is presented in Figure 4. 


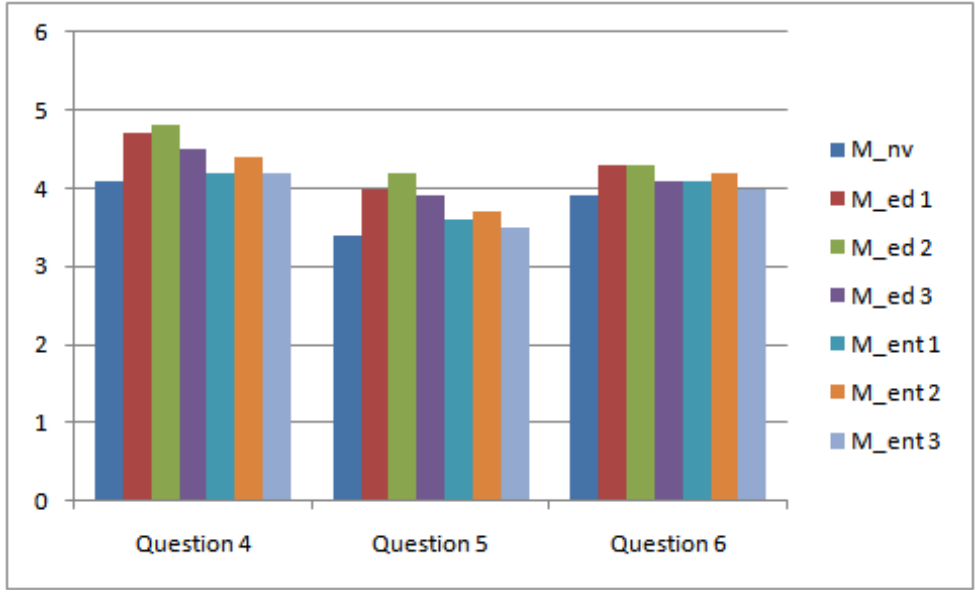

Figure 4. An illustration of MOS results for questions 4, 5 and 6.

Demographic data analysis confirmed that there were slight differences between male and female students in terms of quality of experience with e-learning. Female students were a little more satisfied if supplementary video material was used within the lecture presentation.

\section{Conclusion}

This research aims to present the positive effects of the use of videos as a supplementary teaching tool. Students' motivation and efficiency of learning may be increased if supplementary videos are used.

The analysis of methods for inserting video clips regarding different positions and the context of supplementary content shows that the methodology of inserting the supplementary videos is very important for improvement of teaching.

The positive effects of segmentation as an instructional method of teaching was confirmed with experimental results. Students acquired a higher level of knowledge if the lecture was presented in segments separated with videos, regardless of the context of the video content.

Research also demonstrated the importance of adequate design and presentation of multimedia teaching materials. Different contexts of use of supplementary video content in teaching showed that better efficiency is achieved if the educational content congruent with the lecture has been displayed. Entertainment video was not as efficient as educational, but it can be used to engage and motivate students' learning. 
The position of inserted video has an important role in increasing efficiency of learning. The entertainment video at the beginning of the lecture motivated students towards learning, so testing results were better for that method than if a lecture without videos was used. A better effect was achieved when educational video content was used. This research showed that the most efficient method of use of supplementary video is integration of educational video content in the middle of the lecture.

Positive feedback from students about enhancement of their learning motivation and results of performed testing confirmed positive effects of the use of videos in teaching. Subjective assessment of quality of experience achieved by the use of supplementary video in teaching confirmed that the educational video inserted in the middle of the lecture may increase efficiency of learning. The results indicate that female students are more interested than male students to use learning material enriched by supplementary videos.

In further research we are planning to investigate different aspects of integrating video content into a presentation (duration of video, usage of video streaming, interactive video content, etc.). 


\section{References}

Berk, R. A. (2009). Multimedia teaching with video clips: TV, movies, YouTube, and $\mathrm{mtvU}$ in the college classroom. International J ournal of Technology in Teaching and Learning, 5(1), 1- 21.

Borko, H., J acobs, J ., Eiteljorg, E., \& Pittman, M. E. (2008). Video as a tool for fostering productive discussions in mathematics professional development. Teaching and Teacher Education, 24, 417-436.

Bravo, E., Amante-Garcia, B., Simo, P., Enache, M., \& Fernandez, V. (2011). Video as a new teaching tool to increase student motivation. In Proceedings of 2011 IEEE Global Engineering Education Conference, 638-642.

Burke, S. C., Snyder, S. L., \& Rager R. C. (2009). An assessment of faculty usage of YouTube as a teaching resource. Internet J ournal of Allied Health Sciences and Practice, 7(1), 1-8.

Gardner, H. (2000). Can technology exploit our many ways of knowing?” In D.T. Gordon (Ed.), The digital classroom: How technology is changing the way we teach and learn (pp. 32-35). Cambridge, MA: Harvard College.

De J ong, T. (2010). Cognitive load theory, educational research, and instructional design: Some food for thought. Instructional Science, 38(2), 105-134.

Donkor, F. (2011). Assessment of learner acceptance and satisfaction with video-based instructional materials for teaching practical skills at a distance. The International Review of Research in Open and Distance Learning, 12(5), 7492. Retrieved from http:// www.irrodl.org/index.php/irrodl/article/ view/ 953/ 1859

Hsin, W. J ., \& Cigas, J . (2013). Short videos improve student learning in online education. J ournal of Computing Sciences in Colleges, 28(5), 253-259.

Isman, A., Abanmy,F. A., Hussein, H. B., \&Al Saadany, M. A. (2012). Effectiveness of instructional design model (Isman - 2011) in developing the planning teaching skills of teachers college students' at King Saud University. Turkish Online J ournal of Educational Technology, 11(1), 71-78.

ITU-T Rec. P.910, (1999).Subjective video quality assessment methods for multimedia applications, Geneva.

Kay, R. 2012. Exploring the use of video podcasts in education: A comprehensive review of the literature. Computers in Human Behavior, 28, 820--831. 
Le Callet, P., Moller, S., \& Perkis, A. (2012). Qualinet white paper on definitions of quality of experience. Retrieved from

http:// www.qualinet.eu/images/ stories/ whitepaper v1. 1 dagstuhl output corrected.pdf

Ljubojevic, M., Vaskovic, V., \& Starcevic, D. (2013). The analysis of the users' response to the linear internet video advertising by using QoE methods. J ournal of Universal Computer Science, 19(12), 1736-1760.

Marques, J.C., Quintela, J., Restivo, M.T., \&Trigo, V. (2012). The use of video clips in engineering education. In Proceedings of Interactive Collaborative Learning (ICL), 2012 15th International Conference, 1 - 4.

Mayer, R. E. (2001). Multimedia learning. New York: Cambridge University Press.

McConville, S. A., \& Lane, A. M. (2006). Using on-line video clips to enhance selfefficacytoward dealing with difficult situations among nursing students. Nurse Education Today, 26(3), 200-208.

Moreno, R., \& Mayer, R. E. (1999). Cognitive principles of multimedia learning: The role of modality and contiguity. J ournal of Educational Psychology, 91, 358-368

Olson, T., \&Wisher, R. (2002). The effectiveness of web-based instruction: An initial inquiry. The International Review Of Research In Open And Distance Learning, 3(2). Retrieved from http:// www.irrodl.org/index.php/irrodl/article/view/ 103/ 182

Pryor, C. R., \& Bitter, G. G. (2008). Using multimedia to teach inservice teachers: Impacts on learning, application, and retention. Computers in Human Behavior, 24(6), 2668-2681

Roach, V., \&Lemasters, L. (2006). Satisfaction with online learning: a comparative descriptive study. J ournal of Interactive Online Learning, 5(3), 317-332.

Ruiji, L. (2012). The development on multimedia teaching resources based on information processing theory. International J ournal of Advancements in Computing Technology, 4(2), 58-64.

Spanjers, I. A. E., Wouters, P., Van Gog, T.,\&Merriënboer, J .J . G. (2011). An expertise reversal effect of segmentation in learning from animated worked-out examples. Computers in Human Behavior, 27,46- 52.

Steffes, E. M., \& Duverger, P. (2012). Edutainment with videos and its positive effect on long term memory. Journal for Advancement of Marketing Education, 20(1). 
Stiubiener, I., Silveira, R.M., Matushima, R., Bressan, G., \& Ruggiero, W.V. (2012). Evaluating the effectiveness of the use of teaching materials in video format in distance learning environments. In Frontiers in Education Conference Proceedings 2012, 1-6.

Valle, A., Cabanach, R. , Nunez, J ., Gonzalez-Pienda, J ., Rodriguez, S., \& Pineiro, I. (2003). Cognitive, motivational, and volitional dimensions of learning. Research in Higher Education, 44, 557-580.

\section{Athabasca University $\mathbf{Z}$}

(C) 